\title{
Rate and Time to Develop First Central Line-Associated Bloodstream Infections When Comparing Open and Closed Infusion Containers in a Brazilian Hospital
}

\begin{abstract}
Margarete Vilins ${ }^{1}$, Sergio Blecher ${ }^{1}$, Maria A. Maretti da Silva ${ }^{1}$, Victor Daniel Rosenthal ${ }^{2}$, Kerry Barker ${ }^{3}$ and Reinaldo Salomao ${ }^{1,4}$ ${ }^{1}$ Santa Marcelina Hospital, Sao Paulo, SP, Brazil; ${ }^{2}$ Medical College of Buenos Aires, Argentina; ${ }^{3}$ Statistics, Epidemiology, and Surveillance, Baxter, Round Lake, IL, USA; ${ }^{4}$ Escola Paulista de Medicina, Universidade Federal de Sao Paulo, SP, Brazil
\end{abstract}

\begin{abstract}
The objective of the study was to determine the effect of switching from an open (glass or semi-rigid plastic) infusion container to a closed, fully collapsible plastic infusion container (Viaflex ${ }^{\circledR}$ ) on rate and time to onset of central lineassociated bloodstream infections (CLABSI). An open-label, prospective cohort, active healthcare-associated infection surveillance, sequential study was conducted in three intensive care units in Brazil. The CLABSI rate using open infusion containers was compared to the rate using a closed infusion container. Probability of acquiring CLABSI was assessed over time and compared between open and closed infusion container periods; three-day intervals were examined. A total of $\mathbf{1 1 2 5}$ adult ICU patients were enrolled. CLABSI rate was significantly higher during the open compared with the closed infusion container period (6.5 versus $3.2 \mathrm{CLABSI} / 1000 \mathrm{CL}$ days; $\mathrm{RR}=0.49,95 \% \mathrm{CI}=0.26$ 0.95, $\mathrm{p}=\mathbf{0 . 0 3 1}$ ). During the closed infusion container period, the probability of acquiring a CLABSI remained relatively constant along the time of central line use $(0.8 \%$ Days $2-4$ to $0.7 \%$ Days $11-13)$ but increased in the open infusion container period (1.5\% Days 2-4 to 2.3\% Days 11-13). Combined across all time intervals, the chance of a patient acquiring a CLABSI was significantly lower $(55 \%)$ in the closed infusion container period (Cox proportional hazard ratio $0.45, p=0.019)$. CLABSIs can be reduced with the use of full barrier precautions, education, and performance feedback. Our results show that switching from an open to a closed infusion container may further reduce CLABSI rate as well as delay the onset of CLABSIs. Closed infusion containers significantly reduced CLABSI rate and the probability of acquiring CLABSI.
\end{abstract}

Key-Words: Bacteremia, central line-associated blood stream infections, intensive care unit, healthcare-associated infection, intravascular device.

The majority of primary bloodstream infections (BSI) originate from central lines (CLs) and present a significant risk for hospitalized patients, particularly for those in intensive care units (ICUs). Central line-associated blood stream infections (CLABSI) extend hospitalization, and increase both associated costs and mortality [1].

Intravenous (IV) fluid contamination may occur during setup, admixture preparation, and administration [2,3]. Additional risks for extrinsic contamination are incurred when the infusion system is vented, as is the case with open infusion containers.

Two types of IV infusion systems (open and closed) are in use worldwide [4,5]. Open infusion containers consist of rigid (glass, burette) or semi-rigid plastic containers that must admit air (air filter or needle) in order to empty the solution from the container. Closed infusion containers consist of fully collapsible plastic bags that do not require or use any external vent (air filter or needle) to empty the solution, and the injection ports are self-sealing. Closed infusion containers ensure a consistent, even infusion rate throughout the administration process without the

Received on 16 March 2009; revised 19 September 2009.

Address for correspondence: Dr.Reinaldo Salomao. Department of Medicine, EPM-Unifesp, Phone: 55112070 6347. Fax: 55112070634. E-mail: rsalomao@unifesp.br. Financial Support: Financial support. Baxter Healthcare provided financial support to Dr. Rosenthal to serve as the Infection Control Coordinator for this study. The budget for conducting the trial was donated to Hospital Santa Marcelina by the local investigators. Dr. Salomao has also served as a consultant to Baxter Healthcare.

The Brazilian Journal of Infectious Diseases 2009;13(5):335-340. (C) 2009 by The Brazilian Journal of Infectious Diseases and Contexto Publishing. All rights reserved. assistance of a mechanical device (e.g., infusion pump). Product integrity must be maintained during extreme usage conditions and there should be no leakage.

Closed systems are being incorporated into standard practice to prevent CLABSI. Numerous countries have reported CLABSI outbreaks resulting from contaminated infusate in open infusion systems [2,6-10]. Other studies have established extrinsic or in-use contamination as the most significant contributing factor in the bacterial contamination of infusion systems $[11,12]$. In a study conducted in Argentina, switching from open (semi-rigid plastic) to closed infusion containers resulted in a $64 \%$ reduction in the rate of CLABSI [5].

The impact of switching from an open to a closed infusion container on CLABSI has not been previously investigated in Brazil. In this study, we report the results of a prospective, sequential study undertaken to determine the impact of switching from an open (glass or semi-rigid plastic) to a closed infusion container on both the rate and time to onset of CLABSI in Brazil.

\section{Material and Methods}

Setting

This study was conducted in three ICUs at Santa Marcelina Hospital, a teaching hospital in Sao Paulo, Brazil, with the approval of the hospital Ethics Committee. The hospital has an active infection control program, with two physicians trained in infectious diseases and three infection control nurses. The three ICUs operate at the highest level of complexity in Brazil, providing treatment for medical, surgical, and trauma patients. 


\section{Data Collection}

Patients who had a CL in place for $\geq 24$ hours were enrolled from each of the study ICUs. Patient gender, average severity-of-illness score on ICU entry [13], device utilization, antibiotic exposure, and all active infections identified while in the ICU were prospectively recorded on case report forms by a trained nurse. Blood cultures were obtained at the discretion of the patients' physicians. Standard laboratory methods were used to identify microorganisms recovered from positive blood cultures [14].

\section{Definitions}

United States Centers for Disease Control (CDC) National Nosocomial Infections Surveillance Systems (NNIS) program definitions were used to define device-associated infections: CLABSI was defined as either laboratory confirmed BSI (LCBSI) or clinical primary nosocomial sepsis (CSEP) [15].

An open infusion container was defined as a rigid (glass, burette) or semi-rigid plastic container that must admit air to empty (air filter or needle). A closed infusion container was defined as a fully collapsible, plastic bag that does not require or use any external vent (air filter or needle) to empty the solution, and has injection ports that are self-sealing.

\section{Investigational Products}

Baxter Viaflex® (Baxter Hospitalar Ltda, Brazil), a fully collapsible plastic bag, was used during the closed infusion container period. Commercially available open infusion containers (glass and semi-rigid plastic containers) were used during the open infusion container period.

\section{Study Design}

Active surveillance for CLABSI and compliance with infection control practices were conducted throughout the study using CDC NNIS methodologies, definitions, and criteria [13]. The open infusion container period was followed by the closed infusion container period. The open infusion container period lasted 7 months (March 2004 to October 2004). This was followed by a closed infusion container period of the same duration (November 2004 to April 2005).

Hand hygiene compliance prior to patient contact, aseptic procedures [16], placement of gauze on CL insertion sites, condition of gauze dressing (absence of blood, moisture, and gross soilage; occlusive coverage of insertion site) $[17,18]$, and documentation for date of CL insertion were assessed during the study. Healthcare workers (physicians, nurses, and paramedical staff) were observed three times weekly across all work shifts by a research nurse who recorded relevant information on a standard form.

\section{Data Analysis}

Outcomes measured during the open and closed infusion container periods included the incidence density rate of CLABSI (number of cases per $1000 \mathrm{CL}$ days) and time to CLABSI. Chi-square analyses for dichotomous variables and t-test for continuous variables were used to analyze baseline differences between container periods. Relative risk (RR) ratios, 95\% confidence intervals (CIs), and P-values were determined for all outcomes. Time to first CLABSI was analyzed using a log-rank test and is presented graphically using Kaplan-Meier curves. Simple life table conditional probabilities also are presented graphically to help explain the changing risk of infection over time (Figure 1).

\section{Results}

A total of 1,125 patients were enrolled in the study: 483 during the open infusion container period and 642 during the closed infusion container period. Patients in both container periods were statistically similar with respect to demographics, average severity of illness score, and underlying illness (except for endocrine disease, cardiac failure, cardiac surgery, chronic obstructive pulmonary disease, abdominal surgery, immunocompromise, and urinary catheter and mechanical ventilator exposure) (Table 1 ).

Hand hygiene compliance exceeded 60\% during both periods (65.4\% and 63.9\% during the open and closed infusion container periods, respectively, $\mathrm{RR}=0.98$; and $95 \% \mathrm{CI}=0.94-1.02$ ).

Presence of gauze at the CL site was $99.5 \%$ and $100 \%$ during the open and closed infusion container periods, respectively $(\mathrm{RR}=1.01 ; 95 \% \mathrm{CI}=1.00-1.01)$. Compliance with protocol-prescribed condition of gauze was $98.6 \%$ and 99.7\% during the open and closed infusion container periods, respectively $(\mathrm{RR}=1.01 ; 95 \% \mathrm{CI}=1.01-1.02)$. Presence of the date at the CL insertion site/administration set was 100\% during both the open and closed infusion container periods.

Both the incidence density rate and the percentage of patients with CLABSI were statistically significantly lower in the closed compared to the open infusion container period (Table 2). The distribution of microorganisms during both container periods is shown in Table 3.

In this study, we compared the open and closed infusion container periods with respect to time to acquisition of first CLABSI (Table 4). When examined at three-day intervals, the conditional probability of acquiring a CLABSI during the closed infusion container period was observed to be relatively constant (Table 4). During the open infusion container period, the conditional probability of acquiring a CLABSI was higher in each three-day interval compared to the corresponding three-day intervals in the closed infusion container period. The conditional probability of acquiring a CLABSI in the open infusion container period ranged from $1.5 \%$ at Days $2-4$ to $2.3 \%$ at Days 11-13. Combined across all time intervals, the chance of a patient acquiring a CLABSI was significantly lower (55\%) in the closed infusion container period (Cox proportional hazard ratio 0.45, $\mathrm{p}=0.019$ ). Cumulative results are shown in Figure 1.

\section{Discussion}

Seriously ill patients frequently require CL access for administration of large volumes of IV fluid, medications, and blood products, or for hemodynamic monitoring. It is well 
Table 1. Patient demographics, underlying illness, length of stay, device utilization, and antibiotic usage during the two study periods.

\begin{tabular}{|c|c|c|c|c|c|}
\hline & $\begin{array}{c}\text { Open infusion } \\
\text { container }(\mathrm{N}=483) \\
\%(n)\end{array}$ & $\begin{array}{c}\text { Closed infusion } \\
\text { container }(\mathrm{N}=642) \\
\%(\mathrm{n})\end{array}$ & $\mathbf{R R}$ & $95 \% \mathrm{CI}$ & P-value \\
\hline Sex (Male) & $56.3 \%(272 / 483)$ & $56.7 \%(364 / 642)$ & 1.01 & $0.91-1.12$ & 0.90 \\
\hline Sex (Female) & 43.7\%(211/483) & 43.3\%(278/642) & 0.99 & $0.87-1.13$ & - \\
\hline Endocrine Disease & 16.8\%(81/483) & $12.6 \%(81 / 642)$ & 0.75 & $0.57-1.00$ & 0.05 \\
\hline Cardiac Failure & $35.6 \%(172 / 483)$ & 29.9\%(192/642) & 0.84 & $0.71-0.99$ & 0.04 \\
\hline Angina Pectoris & $3.3 \%(16 / 483)$ & $1.9 \%(12 / 642)$ & 0.56 & $0.27-1.18$ & 0.12 \\
\hline Cardiac Surgery & $1.9 \%(9 / 483)$ & $0.5 \%(3 / 642)$ & 0.25 & $0.07-0.92$ & 0.02 \\
\hline COPD & $1.0 \%(5 / 483)$ & $0.0 \%(0 / 642)$ & - & - & $<0.01$ \\
\hline Cancer & $0.4 \%(2 / 483)$ & $0.0 \%(0 / 642)$ & - & - & 0.10 \\
\hline Renal Impairment & $3.9 \%(19 / 483)$ & $3.0 \%(19 / 642)$ & 0.75 & $0.40-1.41$ & 0.37 \\
\hline Hepatic Failure & $0.0 \%(0 / 483)$ & $0.0 \%(0 / 642)$ & & & \\
\hline Abdominal Surgery & $0.8 \%(4 / 483)$ & $0.0 \%(0 / 642)$ & - & - & 0.02 \\
\hline Thoracic Surgery & $0.0 \%(0 / 483)$ & $0.0 \%(0 / 642)$ & - & - & - \\
\hline Trauma & $0.0 \%(0 / 483)$ & $0.2 \%(1 / 642)$ & - & - & 0.39 \\
\hline Previous Infection & 6.8\%(33/483) & $6.4 \%(41 / 642)$ & 0.93 & $0.60-1.46$ & 0.77 \\
\hline Stroke & $0.0 \%(0 / 483)$ & $0.0 \%(0 / 642)$ & - & - & - \\
\hline Immunocompromise & $0.0 \%(0 / 483)$ & $1.2 \%(8 / 642)$ & - & - & 0.01 \\
\hline Urinary catheter & 76.2\%(368/483) & $67.0 \%(430 / 642)$ & 0.88 & $0.82-0.95$ & $<0.01$ \\
\hline \multirow[t]{2}{*}{ Mechanical ventilator } & $56.3 \%(272 / 483)$ & $47.4 \%(304 / 642)$ & 0.84 & $0.75-0.94$ & $<0.01$ \\
\hline & Mean \pm SD & Mean \pm SD & & & \\
\hline ICU stay (days) & $9.9 \pm 12.10$ & $7.9 \pm 8.57$ & - & - & $<0.01$ \\
\hline Age (yrs) & $54.6 \pm 18.72$ & $56.0 \pm 16.75$ & - & - & 0.20 \\
\hline Severity-of-illness score & $3.7 \pm 0.92$ & $3.7 \pm 0.86$ & - & - & 0.32 \\
\hline \multirow[t]{2}{*}{ CL utilization per patient (days) } & $8.9 \pm 15.56$ & $6.3 \pm 9.48$ & - & - & $<0.01$ \\
\hline & $\begin{array}{l}\text { Defined daily } \\
\text { dose (DDD) }\end{array}$ & $\begin{array}{c}\text { Defined daily } \\
\text { dose (DDD) }\end{array}$ & & & \\
\hline Antibiotic use per 1000 days & 2287 & 2408 & 1.05 & $1.01-1.10$ & 0.01 \\
\hline
\end{tabular}

SD, Standard deviation; COPD, chronic obstructive pulmonary disease.

Table 2. Incidence of CLABSI during the two study periods.

\begin{tabular}{lccccc}
\hline & $\begin{array}{c}\text { Open infusion } \\
\text { container }(\mathbf{n}=\mathbf{4 8 3})\end{array}$ & $\begin{array}{c}\text { Closed infusion } \\
\text { container }(\mathbf{n}=\mathbf{6 4 2})\end{array}$ & $\mathbf{R R}$ & $\mathbf{9 5 \%} \mathbf{C I}$ & p-value \\
\hline CL days no. & 4,297 & 4,041 & - & - & - \\
CLABSI no. & 28 & 13 & - & - & - \\
CLABSI per 1000 days & 6.5 & 3.2 & 0.49 & $0.26-0.95$ & 0.03 \\
Percentage of patients & 5.8 & 2.0 & 0.35 & $0.18-0.67$ & $<0.01$ \\
with CLABSI & & & & & \\
\hline
\end{tabular}

no., number; CL, central line; CLABSI, central line-associated bloodstream infection.

known that the use of CLs poses a significant increase in the risk of CLABSI [4,19-23].

In various studies, increases in length of stay, cost, and attributable mortality have all been reported as consequences of CLABSI [1,24-27]. In Argentina, Rosenthal et al. found that CLABSI resulted in an extra 12 days of hospitalization and 4,888 US dollars in costs [1]. Likewise, Higuera et al. reported that CLABSI in Mexico resulted in an extra six days of hospitalization and 11,560 US dollars in costs [25].
CLABSIs are apparently related to increased attributable mortality: Collignon [28] reported that CLABSIs resulted in excess mortality of $12 \%$ in Australia, while Pittet et al. $[29,30]$ found an attributable mortality of $25 \%$ in a study conducted in the United States. Similarly, CLABSIs are responsible for excess mortality in both South and Central America. In a study of medical/surgical ICUs in Argentina, Rosenthal et al. found an attributable mortality rate of 25\% [31], and in a recent study of ICUs in Mexico, Higuera et al. [25] found an attributable mortality rate of $20 \%$. 
Figure 1. Cumulative Probability of CLABSI displayed by days on CL.

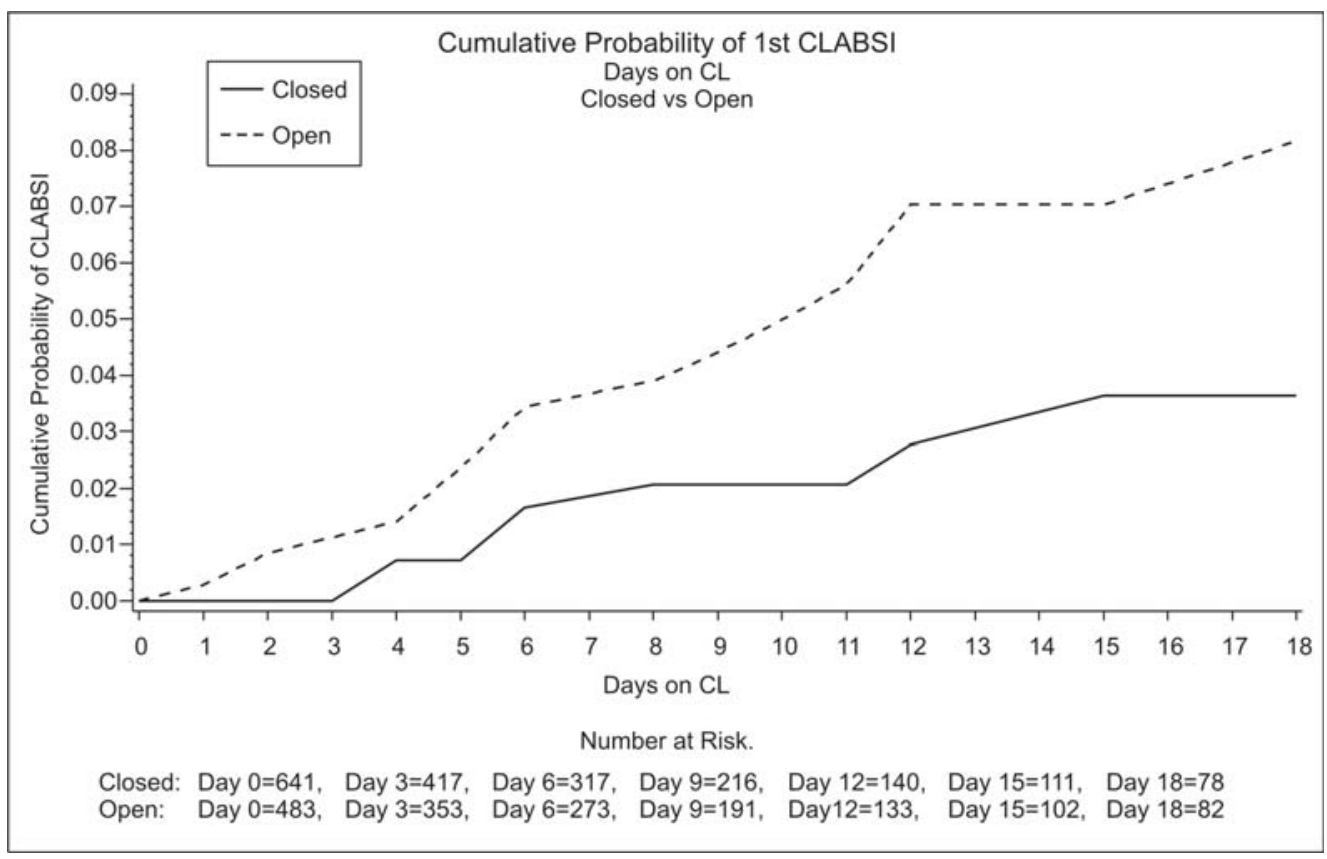

Table 3. Microbial profile of CLABSI during the two study periods.

\begin{tabular}{lcc}
\hline Microorganism & Open infusion container & Closed infusion container \\
\hline Culture documented BSI & 28 & 13 \\
Gram-positive bacteria. $\mathrm{n}(\%)$ & $15(53.6 \%)$ & $10(76.9 \%)$ \\
$\quad$ Staphylococcus aureus & 4 & 9 \\
Coagulase-negative staphylococci & 9 & 1 \\
Enterococci species & 2 & 0 \\
Gram-negative bacteria. $n(\%)$ & $11(39.3 \%)$ & $3(23.1 \%)$ \\
Acinetobacter species & 4 & 2 \\
Alcaligenes species & 1 & 0 \\
Enterobacter species & 3 & 0 \\
Klebsiella species. & 3 & 1 \\
Yeasts n (\%) & $2(7.1 \%)$ & 0 \\
Candida species & 2 & 0 \\
\hline
\end{tabular}

BSI, bloodstream infectio

Table 4. Analysis of time to first CLABSI infection by CL day intervals.

\begin{tabular}{|c|c|c|c|c|c|c|}
\hline CL Days Interval & $0-1$ & $2-4$ & $5-7$ & 8-10 & 11-13 & Total \\
\hline \multicolumn{7}{|l|}{ Open infusion container } \\
\hline Number of CLABSI during interval & 0 & 5 & 6 & 3 & 3 & 27 \\
\hline Number censored during interval & 127 & 40 & 99 & 52 & 38 & \\
\hline Number at risk (entering interval) * & 483 & 356 & 311 & 206 & 151 & \\
\hline Conditional probability during interval & 0 & 0.01488 & 0.02294 & 0.01667 & 0.02273 & \\
\hline \multicolumn{7}{|l|}{ Closed infusion container } \\
\hline Number of CLABSI during interval & 0 & 3 & 3 & 1 & 1 & 12 \\
\hline Number censored during interval & 224 & 49 & 120 & 79 & 42 & \\
\hline Number at risk (entering interval) * & 641 & 417 & 365 & 242 & 162 & \\
\hline Conditional probability during interval & 0 & 0.00764 & 0.00984 & 0.00494 & 0.00709 & \\
\hline Difference in conditional probability opened vs. closed & 0 & 0.00724 & 0.01311 & 0.01173 & 0.01564 & \\
\hline
\end{tabular}

$\mathrm{CL}$, central line; CLABSI, central line-associated bloodstream infection. 
CLABSIs can be prevented [32,33]. Simple interventions such as use of maximal barrier precautions [34] and use of chlorhexidine rather than iodophors for cutaneous antisepsis [35] have resulted in decreased incidence of CLABSI in randomized trials [34]. Performance monitoring and feedback were also effective in reducing rates of CLABSI $[17,18]$.

In a study conducted in a medical ICU of Brazil by Lobo et al., the rate of CLABSI was 20.0 per 1000 CL days. A multifaceted program including an educational strategy targeted to specific problems observed during careful evaluation of CL care practices, decreased the presence of Staphylococcus aureus and nearly halved the CLABSI rate to 11.0 per $1000 \mathrm{CL}$ days. During the year that followed implementation of the educational intervention, the CLABSI rate remained similar at 12.0 per 1000 CL days [36].

Use of closed infusion systems has also reduced the risk of extrinsic contamination during IV administration in the hospital setting. Intrinsic contamination of parenteral fluids (microorganisms introduced during or prior to manufacturing) is almost nonexistent in the United States. Contamination of the infusate or catheter hubs has been associated with most epidemics of infusion-related CLABSIs. However, in several countries, hospitals continue to use open (glass, burette, or semi-rigid plastic), externally vented (with or without air filters) infusion containers, thereby increasing the risk of extrinsic contamination, especially by Gram-negative bacilli, which can multiply rapidly in commercial IV admixtures [3,6,37-39]. Closed infusion containers have been developed to reduce this risk. However, as published in other studies, open systems are still widely used in a number of hospitals in different countries [4,19-21,31,40].

In this study, open infusion containers were associated with a higher rate of CLABSI which was reduced significantly when switching to a closed infusion containers. The magnitude of the difference in CLABSI rate between the open versus closed infusion container increased over time. Looking at the CLABSI rate per $1000 \mathrm{CL}$ days, only the closed infusion container period achieved levels reported in the NNIS.

Prior investigation published in 2004 did not include analysis of time to CLABSI [5]. In our study, we demonstrated that if the patient receives infusate via an open infusion container, the risk of acquiring CLABSI increases over time. When using a closed infusion container, the probability of acquiring a CLABSI remains relatively constant, and if the patient acquires a CLABSI, it would occur significantly latter; suggesting that closed infusion containers reduce risk of CLABSI acquisition over time. Subsequently, the use of a closed infusion containers could especially benefit those patients with more severe illness who may require CLs for longer periods of time. The delayed onset of CLABSI may also benefit patients with CLs early during the course of treatment when their underlying illness might be most severe.

There were limitations in this study. Participants were not concurrently randomized to the two infusion containers (open and closed). It was logistically not practical to blind the study.
However, this may have mitigated the selection bias that might occur in an open label, randomized study. Also, the study design did not allow for determination of epidemiologic mechanisms responsible for the striking differences in outcome (e.g., reduced contamination of infusate).

\section{Conclusion}

In this study we have shown that switching from an open to a closed infusion container (fully collapsible plastic bag with no requirement for/use of external venting [air filter or needle], and self-sealing injection ports), as adopted in developed countries in North America and Western Europe, significantly diminishes the rate and risk of CLABSI.

\section{Acknowledgements}

We are in debt to Eni Hilario da Silva for patients' data collection. Baxter Brazil sponsored this study at Santa Marcelina Hospital in Sao Paulo, Brazil, and provided Baxter Viaflex ${ }^{\circledR}$ products. We acknowledge the many healthcare professionals at Santa Marcelina Hospital who helped make this study possible. Baxter Healthcare provided financial support to Dr. Victor Rosenthal to serve as the Infection Control Coordinator for this study. The budget for conducting the trial was donated to Hospital Santa Marcelina by the local investigators. Technical writing assistance was provided by Delta Pharma, LP.

\section{References}

1. Rosenthal VD, Guzman S, Migone O, Crnich CJ. The attributable cost, length of hospital stay, and mortality of central lineassociated bloodstream infection in intensive care departments in Argentina: A prospective, matched analysis. Am J Infect Control 2003; 31 (8):475-80.

2. Macias AE, Munoz JM, Bruckner DA, et al. Parenteral infusions bacterial contamination in a multi-institutional survey in Mexico: considerations for nosocomial mortality. Am J Infect Control 1999; 27 (3):285-90.

3. Maki DG, Anderson RL, Shulman JA. In-use contamination of intravenous infusion fluid. Appl Microbiol 1974; 28 (5):77884.

4. Rosenthal VD, Maki DG, Salomao R, et al. Device-associated nosocomial infections in 55 intensive care units of 8 developing countries. Ann Intern Med 2006; 145 (8):582-91.

5. Rosenthal VD, Maki DG. Prospective study of the impact of open and closed infusion systems on rates of central venous catheterassociated bacteremia. Am J Infect Control 2004; 32 (3):13541.

6. Maki DG, Rhame FS, Mackel DC, Bennett JV. Nationwide epidemic of septicemia caused by contaminated intravenous products. I. Epidemiologic and clinical features. Am J Med 1976; 60 (4):47185.

7. Goldmann DA, Dixon RE, Fulkerson CC, et al. The role of nationwide nosocomial infection surveillance in detecting epidemic bacteremia due to contaminated intravenous fluids. Am J Epidemiol 1978; 108 (3):207-13.

8. Munoz JM, Macias AE, Guerrero FJ, et al. [Control of pediatric nosocomial bacteremia by a program based on culturing of parenteral solutions in use]. Salud Publica Mex 1999; 41 Suppl $1:$ S32-7.

9. Centers for Disease Control. Clinical sepsis and death in a newborn nursery associated with contaminated parenteral medicationsBrazil, 1996. MMWR Morb Mortal Wkly Rep 1998; 47 (29):610-2. 
10. Matsaniotis NS, Syriopoulou VP, Theodoridou MC, Tzanetou KG, Mostrou GI. Enterobacter sepsis in infants and children due to contaminated intravenous fluids. Infect Control 1984; 5 (10):471-7.

11. Kilian J, Hosch A, Ahnefeld FW, Schmitz JE, Vanek E. [Bacterial contamination as a complication of intravenous therapy in intensive care (author’s transl)]. Anaesthesist 1980; 29 (10):55966.

12. McAllister JC, Buchanan EC, Skolaut MW. A comparison of the safety and efficiency of three intermittent intravenous therapy systems - the minibottle, the minibag and the inline burette. Am J Hosp Pharm 1974; 31 (10):961-7.

13. Emori TG, Culver DH, Horan TC, et al. National nosocomial infections surveillance system (NNIS): description of surveillance methods. Am J Infect Control 1991; 19 (1):19-35.

14. Balows A, Hausler W, eds. Manual of Clinical Microbiology. 5th Ed. Washington DC: American Society of Microbiology; 1991.

15. Garner JS, Jarvis WR, Emori TG, Horan TC, Hughes JM. CDC definitions for nosocomial infections, 1988. Am J Infect Control 1988; 16 (3):128-40.

16. Rosenthal VD, McCormick RD, Guzman S, Villamayor C, Orellano PW. Effect of education and performance feedback on handwashing: the benefit of administrative support in Argentinean hospitals. Am J Infect Control 2003; 31 (2):8592.

17. Rosenthal VD, Guzman S, Pezzotto SM, Crnich CJ. Effect of an infection control program using education and performance feedback on rates of intravascular device-associated bloodstream infections in intensive care units in Argentina. Am J Infect Control 2003; 31 (7):405-9.

18. Higuera F, Rosenthal VD, Duarte P, et al. The effect of process control on the incidence of central venous catheter-associated bloodstream infections and mortality in intensive care units in Mexico. Crit Care Med 2005; 33 (9):2022-7.

19. Ramirez Barba EJ, Rosenthal VD, Higuera F, et al. Deviceassociated nosocomial infection rates in intensive care units in four Mexican public hospitals. Am J Infect Control 2006; 34 (4):244-7.

20. Moreno CA, Rosenthal VD, Olarte N, et al. Device-associated infection rate and mortality in intensive care units of 9 Colombian hospitals: findings of the International Nosocomial Infection Control Consortium. Infect Control Hosp Epidemiol 2006; 27 (4):349-56.

21. Rosenthal VD, Guzman S, Crnich C. Device-associated nosocomial infection rates in intensive care units of Argentina. Infect Control Hosp Epidemiol 2004; 25 (3):251-5.

22. Diener JR, Coutinho MS, Zoccoli CM. [Central venous catheterrelated infections in critically ill patients]. Rev Assoc Med Bras 1996; 42 (4):205-14.

23. Velasco E, Soares M, Byington R, et al. Prospective evaluation of the epidemiology, microbiology, and outcome of bloodstream infections in adult surgical cancer patients. Eur J Clin Microbiol Infect Dis 2004; 23 (8):596-602.

24. Stone PW, Braccia D, Larson E. Systematic review of economic analyses of health care-associated infections. Am J Infect Control 2005; 33 (9):501-9.
25. Higuera F, Rangel-Frausto MS, Rosenthal VD, et al. Attributable cost and length of stay for patients with central venous catheterassociated bloodstream infection in Mexico City intensive care units: a prospective, matched analysis. Infect Control Hosp Epidemiol 2007; 28 (1):31-5.

26. Digiovine B, Chenoweth C, Watts C, Higgins M. The attributable mortality and costs of primary nosocomial bloodstream infections in the intensive care unit. Am J Respir Crit Care Med 1999; 160 (3):976-81.

27. Rello J, Ochagavia A, Sabanes E, et al. Evaluation of outcome of intravenous catheter-related infections in critically ill patients. Am J Respir Crit Care Med 2000; 162 (3 Pt 1):1027-30.

28. Collignon PJ. Intravascular catheter associated sepsis: a common problem. The Australian Study on Intravascular Catheter Associated Sepsis. Med J Aust 1994; 161 (6):374-8.

29. Pittet D, Tarara D, Wenzel RP. Nosocomial bloodstream infection in critically ill patients. Excess length of stay, extra costs, and attributable mortality. JAMA 1994; 271 (20):1598-601.

30. Heiselman D. Nosocomial bloodstream infections in the critically ill. JAMA 1994; 272 (23):1819-20.

31. Rosenthal VD, Guzman S, Orellano PW. Nosocomial infections in medical-surgical intensive care units in Argentina: attributable mortality and length of stay. Am J Infect Control 2003; 31 (5):291-5.

32. Jarvis WR. The evolving world of healthcare-associated bloodstream infection surveillance and prevention: is your system as good as you think? Infect Control Hosp Epidemiol 2002; 23 (5):236-8.

33. O'Grady NP, Alexander M, Dellinger EP, et al. Guidelines for the prevention of intravascular catheter-related infections. Infect Control Hosp Epidemiol 2002; 23 (12):759-69.

34. Raad, II, Hohn DC, Gilbreath BJ, et al. Prevention of central venous catheter-related infections by using maximal sterile barrier precautions during insertion. Infect Control Hosp Epidemiol 1994; 15 (4 Pt 1):231-8.

35. Maki DG, Ringer M, Alvarado CJ. Prospective randomised trial of povidone-iodine, alcohol, and chlorhexidine for prevention of infection associated with central venous and arterial catheters. Lancet 1991; 338 (8763):339-43.

36. Lobo RD, Levin AS, Gomes LM, et al. Impact of an educational program and policy changes on decreasing catheter-associated bloodstream infections in a medical intensive care unit in Brazil. Am J Infect Control 2005; 33 (2):83-7.

37. Mackel DC, Maki DG, Anderson RL, Rhame FS, Bennett JV. Nationwide epidemic of septicemia caused by contaminated intravenous products: mechanisms of intrinsic contamination. J Clin Microbiol 1975; 2 (6):486-97.

38. Maki DG, Martin WT. Nationwide epidemic of septicemia caused by contaminated infusion products. IV. Growth of microbial pathogens in fluids for intravenous infusions. J Infect Dis 1975; 131 (3):267-72.

39. Maki D, Mermel L. Infections due to infusion therapy. In. Bennett JV, Brachman, PS, eds. Hospital Infections. Fourth ed. Philadelphia: Lippincott-Raven; 1998; p. 611-47.

40. Leblebicioglu H, Rosenthal VD, Arikan OA, et al. Device-associated hospital-acquired infection rates in Turkish intensive care units. Findings of the International Nosocomial Infection Control Consortium (INICC). J Hosp Infect 2007; 65 (3):251-7. 